\title{
EFEITO DA ICTERÍCIA OBSTRUTIVA NA FERTILIDADE, MORFOLOGIA OVARIANA E DESENVOLVIMENTO FETAL EM RATAS
}

\author{
Vivian RESENDE ${ }^{1}$, Andy PETROIANU ${ }^{1}$, Marlene Soares Dias ALVES² e Luiz Ronaldo ALBERTI ${ }^{1}$
}

\begin{abstract}
RESUMO - Avaliou-se o efeito da icterícia obstrutiva na capacidade reprodutiva, morfologia ovariana e desenvolvimento fetal em ratas, utilizando 53 ratas sexualmente maduras, distribuídas em dois grupos: grupo $1(n=28)$ - ligadura do ducto biliopancreático e grupo $2(n=$ 25 ) - controle. Pode-se concluir que, em presença de hiperbilirrubinemia, a fertilização é viável, a capacidade reprodutiva é muito reduzida, os ciclos estrais tornam-se irregulares, o epitélio vaginal permanece cornificado, os corpos lúteos ovarianos regridem, os corpos lúteos gravídicos não são alterados, aumentando progressivamente durante a prenhez, e o desenvolvimento fetal é gravemente alterado. DESCRITORES - Hiperbilirrubinemia. Icterícia obstrutiva. Fertilização. Desenvolvimento fetal. Ciclo estral. Ratos.
\end{abstract}

\section{INTRODUÇÃO}

A colestase específica da gestação ocorre principalmente no terceiro trimestre e desaparece com o término da gravidez. Supõe-se que ocorram mudanças nos sistemas enzimáticos dos hepatócitos, envolvendo o metabolismo das bilirrubinas e sua excreção ${ }^{(1)}$. Nos casos em que essa afecção ocorre, observa-se mais recém-nascidos com sofrimento fetal intra-uterino, além de alto índice de prematuridade ${ }^{(1)}$.

A hiperbilirrubinemia mostrou toxicidade embrionária ao constatar-se diminuição dos locais de implantações de embriões na parede uterina e sua reabsorção quando se implantavam ${ }^{(2)}$. Experimentalmente, o método mais utilizado para obter icterícia obstrutiva é a ligadura do ducto biliar ${ }^{(2)}$.

Considerando as complicações gestacionais, que são mais freqüentes em pacientes com hiperbilirrubinemia e as poucas análises relacionadas a essa condição, realizouse o presente estudo, cujo objetivo foi verificar se há alterações no processo de fertilização e desenvolvimento fetal de ratas com hiperbilirrubinemia.

\section{MÉTODO}

Este estudo foi realizado de acordo com as recomendações das Normas Internacionais de Proteção aos Animais e do Código Brasileiro de Experimentação Animal (1988) e foi aprovado pelo Comitê de Ética em Pesquisa Experimental da Universidade Federal de Minas Gerais.

Foram utilizadas 53 ratas da raça Lewis, sexualmente maduras, com 4 a 5 meses de idade e peso inicial variando entre $191 \mathrm{~g}$ e $220 \mathrm{~g}$. Elas foram mantidas em temperatura e iluminação ambientes, recebendo diariamente água e alimento completo para ratos. Os animais foram aleatoriamente distribuídos em dois grupos:

- grupo $1(\mathrm{n}=28)$ : animais submetidos a ligadura do ducto biliopancreático;

- grupo $2(\mathrm{n}=25)$ : grupo controle - animais submetidos apenas a laparotomia seguida de laparorrafia ("sham operation" - operação simulada).

A regularidade dos ciclos estrais nos animais destinados ao experimento foi avaliada por meio de esfregaços vaginais diários durante 7 dias. Coletou-se o lavado vaginal e fez-se o esfregaço, que foi fixado com álcool-éter 1:1 e corado pelo método de Shorr (1941).

Sob anestesia geral com cloridrato de quetamina $(90 \mathrm{mg} / \mathrm{kg})$ e cloridrato de xilazina $(10 \mathrm{mg} / \mathrm{kg})$, ambos por via intraperitonial, os animais do grupo 1 foram submetidos a laparotomia mediana, ligadura dupla do ducto biliopancreático e sua secção. Os animais do grupo 2 foram submetidos ao mesmo procedimento anestésico, de laparotomia e laparorrafia para simular o efeito do trauma operatório.

No $10^{\circ}$ dia pós-operatório, coletou-se sangue para dosagem quantitativa dos níveis de bilirrubinas circulantes.

A partir do $23^{\circ}$ dia pós-operatório, as ratas foram acasaladas com um macho sabidamente fértil. Nos dias seguintes ao acasalamento, os esfregaços vaginais continuaram a ser feitos diariamente, para verificar a presença da cópula, mediante a observação de espermatozóides. Os animais não copulados permaneceram acasalados durante 15 dias nos quais os esfregaços vaginais continuaram a ser realizados diariamente.

Trabalho realizado no Departamento de Morfologia do Instituto de Ciências Biológicas Universidade Federal de Minas Gerais (UFMG), Belo Horizonte, MG.

${ }^{1}$ Departamento de Cirurgia da Faculdade de Medicina da UFMG; ${ }^{2}$ Departamento de Morfologia do Instituto de Ciências Biológicas da UFMG, Belo Horizonte, MG.

Correspondência: Prof. Andy Petroianu - Av. Afonso Pena, 1626 - apt. 1901 - 30130-005 - Belo Horizonte, MG. - E-mail: petroian@medicina.ufmg.br 
A morte dos animais foi processada após anestesia com cloridrato de quetamina e cloridrato de xilazina no $12^{\circ}$ e $20^{\circ}$ dias após cópula e no $15^{\circ}$ dia após o acasalamento, nos animais em que não se constatou a cópula. As ratas não acasaladas foram mortas 35 dias após a ligadura do ducto biliopancreático, no período de diestro.

Os fetos das ratas com 20 dias de gravidez e que foram submetidas a ligadura do ducto biliopancreático foram macroscopicamente comparados entre si e com aqueles das ratas não operadas, analisando-se seu aspecto morfológico e medida cefalocaudal. A vitalidade dos fetos foi avaliada pela presença de movimentos ativos no momento em que foram removidos do útero, com a rata ainda viva, sob anestesia.

Os ovários foram preparados para estudo histológico pela coloração de hematoxilina-eosina, e tricrômico de Masson. $\mathrm{O}$ número e tamanho dos corpos lúteos foram determinados após examinar cada corpo lúteo em toda sua extensão.

As comparações entre os corpos lúteos, peso dos ovários e peso dos animais foram realizadas utilizando o teste da análise de variância com um fator. Para avaliação da influência da hiperbilirrubinemia na prenhez utilizou-se o teste do qui ao quadrado. Utilizou-se a análise de correlação de Sperman (r) para comparar a proporção de animais com prenhez em relação às concentrações de bilirrubinas. Os dados foram considerados significantes para $P<0,05$.

\section{RESULTADOS}

Todos os animais submetidos a ligadura do ducto biliopancreático apresentaram elevação das bilirrubinas (bilirrubina total de $7,81 \pm 2,68 \mathrm{mg} / \mathrm{dL})$, sendo de $6,61 \pm 2,49$ nos animais não prenhes e de $8,68 \pm 0,47$ nas ratas prenhes $(P>0,05)$. Também não houve diferença com significância estatística entre a bilirrubina direta e indireta nos animais ictéricos $(P>0,05)$. Ao exame macroscópico do abdome, não foi verificada alteração inflamatória que sugerisse colangite ou pancreatite.

A proporção de animais prenhes foi de 39,3\% (11 ratas) no grupo submetido a ligadura do ducto biliopancreático e de $92,0 \%$ no grupo controle (23 ratas) $(P=0,0002)$, mostrando que existe diferença entre os animais com e sem icterícia $(\mathrm{OR}=17,8)(3,04<\mathrm{OR}<135,55)$.

Das 17 ratas com ligadura do ducto biliopancreático que não desenvolveram prenhez, 9 foram copuladas e em 8 não se constatou a cópula. Entre as nove ratas copuladas, duas permaneceram em diestro durante 6 dias após a cópula. As outras sete ratas copuladas apresentaram ciclos estrais atípicos. As 11 ratas que tiveram prenhez permaneceram em diestro após a cópula. Ainda com relação ao grupo 1, entre as oito ratas em que não se constatou a cópula, cinco apresentaram também ciclos estrais atípicos após o acasalamento, com períodos prolongados que variaram entre 4 e 6 dias em proestro ou estro. Nas outras 23 ratas em que se evidenciou a cópula e que tiveram prenhez, houve a permanência em diestro nos 7 dias subseqüentes à cópula.

Em cinco ratas do grupo 1 com 20 dias de prenhez em que se realizou a ligadura do ducto biliopancreático, observaram-se 47 fetos, sendo que, apesar de terem a mesma idade gestacional, eles tiveram diferentes estádios de desenvolvimento, com medida cefalocaudal variando entre 1 e $2 \mathrm{~cm}$. Por outro lado, as ratas do grupo 2 também com 20 dias de prenhez, sem ligadura do ducto biliopancreático, observaram-se 40 fetos com igual tempo de gestação, sendo que os mesmos apresentaram comprimentos com pequena variação de tamanho $(2,1 \mathrm{a} 2,2 \mathrm{~cm})$ e a morfologia externa indicava o mesmo estádio de desenvolvimento. Observouse, ainda, que no grupo 1 alguns fetos estavam tão deformados e pequenos, que não foi possível medi-los. Todos os fetos do grupo 2 apresentaram movimentos ativos no momento em que foram retirados do útero, ao contrário dos fetos do grupo 1 que estavam inativos, sugerindo que estivessem mortos.

Nas ratas grávidas, as células lúteas não diferiram entre os grupos com e sem icterícia, porém seis ratas, que não desenvolveram gravidez do grupo 1, apresentaram somente corpos lúteos em fase de regressão e em outras oito ratas do mesmo grupo somente corpo albicans foram observados.

A Figura 1 representa o diâmetro dos corpos lúteos nos animais dos grupos 1 e 2 em dois períodos da prenhez (12 e 21 dias).

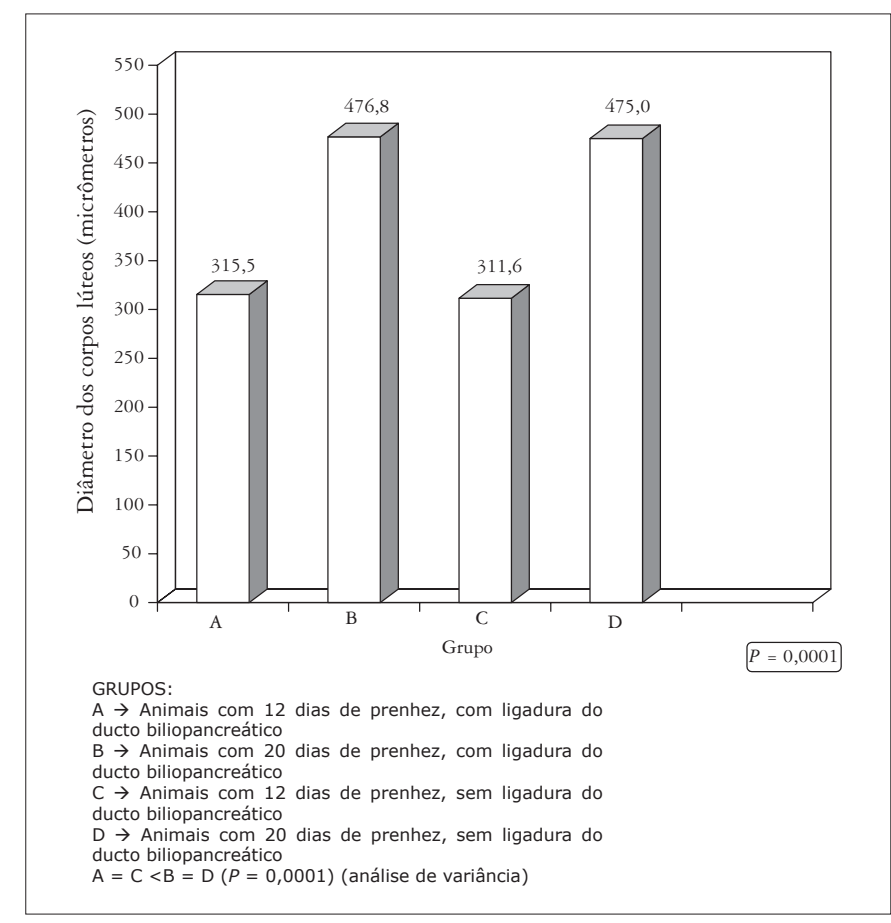

FIGURA 1. Comparação do diâmetro médio (em micrômetros) dos corpos lúteos entre os grupos de interesse

Observa-se que os animais com 20 dias de prenhez apresentaram maior diâmetro do corpo lúteo gravídico em ambos os grupos quando comparados aos animais com 12 dias de prenhez $(P<0,0001)$. Entretanto, não foram verificadas diferenças entre os animais dos grupos 1 e 2, mostrando não haver influência da hiperbilirrubinemia no desenvolvimento do corpo lúteo gravídico.

Em relação ao peso dos ovários, observou-se resultado semelhante ao encontrado no diâmetro do corpo lúteo gravídico, 
onde os animais com 20 dias de prenhez apresentaram maior peso ovariano quando comparados às ratas prenhas com 12 dias $(P<0,0001)$.

Não foi observada correlação significativa entre o peso dos animais e as medidas do diâmetro do corpo lúteo e as medidas do peso dos ovários $(P>0,05)$. Porém, existe correlação significativa entre o diâmetro do corpo lúteo e o peso dos ovários $(P=0,0001$ e $r=0,7038$ ).

\section{DISCUSSÃO}

Determinou-se o acasalamento para após o $23^{\circ}$ dia pósoperatório, por considerar-se tempo suficiente para que os animais sofressem as conseqüências da hiperbilirrubinemia e surgimento da fibrose biliar $^{(3)}$.

Os mecanismos que determinam as alterações reprodutivas em mulheres com doenças hepáticas ainda são pouco elucidados. O presente estudo indica que, em presença de icterícia, ocorre cornificação do epitélio vaginal das ratas. Essa alteração poderia ser causada pela hiperbilirrubinemia, que estimula a elevação de estrogênios livre no plasma, pelo deslocamento de seus locais de ligação na albumina ${ }^{(4)}$.

A constatação de que os diâmetros médios dos corpos lúteos e pesos dos ovários não diferiam entre os animais prenhes operados e não operados sugeriu que a hiperbilirrubinemia não interferiu no desenvolvimento das células lúteas durante a prenhez. O crescimento do corpo lúteo durante a gestação pôde ser comprovado ao se constatar aumento progressivo no peso dos ovários, tamanho das células e corpos lúteos das ratas dos grupos com 12 e 20 dias de prenhez.

O estudo histológico dos ovários das ratas ictéricas desta pesquisa mostrou ausência de corpos lúteos funcionais, sugerindo a existência de anovulação. A permanência desses animais em uma única fase do ciclo estral (proestro ou estro) reforça a hipótese de anovulação. As ratas que apresentavam apenas corpos brancos em seus ovários tinham também grandes folículos com aspecto cístico.

Ratas prenhes permanecem em diestro durante a gestação ${ }^{(4)}$. Nesse período, o principal hormônio secretado pelos corpos lúteos e placenta é a progesterona. Os animais com ligadura do ducto biliopancreático que tiveram prenhez, também permaneceram em diestro, indicando que a hiperbilirrubinemia não interferiu na função secretora dos corpos lúteos gravídicos.

A falta de prenhez em alguns animais copulados pode ter sido decorrente de interferência da hiperbilirrubinemia na fertilização. Outra possibilidade é a ausência de desenvolvimento inicial do ovo ou anomalia em sua implantação ${ }^{(5)}$. Abortamentos imperceptíveis podem ter ocorrido em decorrência de múltiplas más formações, como as detectadas no presente trabalho.

É provável que os fetos com desenvolvimento anormal, como os observados neste estudo, cessaram seu crescimento em fases iniciais do desenvolvimento intra-uterino, uma vez que próximo ao nascimento, todos os fetos tendem a apresentar o mesmo estádio de desenvolvimento. É possível que a passagem das bilirrubinas maternas pelas membranas placentárias contribua para os danos fetais encontrados nesta pesquisa.

\section{CONCLUSÕES}

Concluindo, em presença de icterícia obstrutiva, a fertilização é viável, porém a capacidade reprodutiva é reduzida e os ciclos estrais tornam-se irregulares. Nessa situação, o epitélio vaginal permanece cornificado e os corpos lúteos ovarianos regridem. Quando a prenhez acontece, os corpos lúteos gravídicos não são alterados e aumentam de tamanho progressivamente, porém o desenvolvimento fetal é alterado.

Resende V, Petroianu A, Alves MSD, Alberti LR. Effect of jaundice on fertility, ovarian morphology and fetal development in rats. Arq Gastroenterol. 2008;45(3):249-51.

ABSTRACT - The effect of jaundice on the reproductive capacity, ovarian morphology and fetal development in rats was assessed in 53 sexually mature rats divided into two groups: group $1(\mathrm{n}=28)$ - submitted to ligature of the biliopancreatic duct and group $2(\mathrm{n}=25)$ - control - submitted only to sham operation. In jaundice rats fertilization is viable, the reproductive capacity is intensive reduced, the estrus cycles becomes irregular, the corpi lutea is presented in regression, the gravidic lutea is not modified increasing gradually during the pregnancy and the fetal development is seriously impaired.

HEADINGS - Hyperbilirubinemia. Jaundice, obstructive. Fertilization. Fetal development. Estrous cycle. Rats.

\section{REFERÊNCIAS}

1. Hofmann AF. Biliary secretion and excretion in health and disease: current concepts. Ann Hepatol. 2007;6:15-27.

2. Odegaard I, Stray-Pedersen B, Hallberg K, Haanaes OC, Storrosten OT, Johannesson M. Maternal and fetal morbidity in pregnancies of Norwegian and Swedish women with cystic fibrosis. Acta Obstet Gynecol Scand. 2002;81:698-705.

3. Ropponen A, Sund R, Riikonen S, Ylikorkala O, Aittomaki K. Intrahepatic cholestasis of pregnancy as an indicator of liver and biliary diseases: a population-based study. Hepatology. 2006,43:723-8
4. Rutherford AE, Pratt DS. Cholestasis and cholestatic syndromes. Curr Opin Gastroenterol. 2006,22:209-14.

5. Watchko JF. Hyperbilirubinemia and bilirubin toxicity in the late preterm infant. Clin Perinatol. 2006;33:839-52. 